\title{
Studies on solvent systems for enhanced skin permeation of venlafaxine hydrochloride
}

\author{
Pramod S. Salve*, Shahadev B. Rathod \\ University Department of Pharmaceutical Sciences, Rashtrasant Tukadoji Maharaj Nagpur University Campus, Mahatma Jyotiba Fuley \\ Shaikshanik Parisar Amravati Road, Nagpur -440 033 (M.S.)
}

\begin{abstract}
Venlafaxine hydrochloride $(\mathrm{VH})$ is a serotonin-noradrenaline reuptake inhibitor indicated for treatment of depression disorder. It shows low biological half-life $5 \pm 2 \mathrm{~h}$ and low oral bioavailability $45 \pm 15 \%$ due to extensive hepatic first-pass metabolism. Frequent administration of VH is required to maintain steady state plasma concentration of drug. To overcome hepatic first pass metabolism and to cross blood brain barrier for effectively achieving plasma concentration of $\mathrm{VH}$ in brain, we envisaged to develop transdermal drug delivery system containing VH loaded polymeric nanoparticles. Effect of solvent systems (SS), penetration enhancers (PE), and VH nanoparticles (VHNPs) on transdermal diffusion of drug were studied. VHNPs were prepared by double emulsion solvent evaporation method using high speed homogenizer followed by probe sonication. Poly (lactic-co-glycolic acid) and tween 80 were used as polymer and surfactant respectively. Mean particle size, polydispersity index, zeta potential, entrapment efficiency of optimized VHNPs were found to be $175.4 \mathrm{~nm}, 0.109$, (-) $24 \mathrm{mV}$ and $56 \%$.respectively. Scanning electron microscopy confirmed spherical shape of drug loaded polymeric nanoparticles. SS comprising $50 \%$ PG in EtOH shown maximum flux $158.67 \pm 2.9\left(\mu \mathrm{g} / \mathrm{cm}^{2} / \mathrm{h}\right)$ and lag time was found to be $5.60 \pm 0.16 \mathrm{~h}$. The PE $5(\% \mathrm{v} / \mathrm{v})$ limonene shown maximum flux $200.47 \pm 3.6\left(\mu \mathrm{g} / \mathrm{cm}^{2} / \mathrm{h}\right)$ and lag time $3.17 \pm 0.11 \mathrm{~h}$. The flux and lag time in case of VHNPs were found to be $192.24 \pm 3.20\left(\mu \mathrm{g} / \mathrm{cm}^{2} / \mathrm{h}\right)$ and $4.22 \pm 0.14 \mathrm{~h} \mathrm{respectively}$. Based on flux, clearance and surface area of transdermal patch, a theoretical meaningful plasma level concentration of VH ranging from 12.85 to 128.5 (ng/mL) can be achieved.
\end{abstract}

Keywords: Depression, Venlafaxine hydrochloride, Poly (lactic-co-glycolic acid), Solvent systems, Penetration enhancers, Nanoparticles (NPs)

Article Info: Received 09 June 2019; Review Completed 26 July 2019; Accepted 06 Aug 2019; Available online 18 August 2019

Cite this article as:

Salve PS, Rathod SB, Studies on solvent systems for enhanced skin permeation of venlafaxine hydrochloride, Journal of Drug Delivery and Therapeutics. 2019; 9(4-s):505-518 http://dx.doi.org/10.22270/jddt.v9i4-s.3379

\section{*Address for Correspondence:}

Pramod S. Salve, University Department of Pharmaceutical Sciences, Rashtrasant Tukadoji Maharaj Nagpur University Pramod S. Salve, University Department of Pharmaceutical Sciences,
Campus, Mahatma Jyotiba Fuley Shaikshanik Parisar Amravati Road, Nagpur -440 033 (M.S.)

\section{INTRODUCTION}

Depression is major psychological condition disturbing 340 million people worldwide. Present data shows that $9 \%$ children by age 14 have previously experienced a minimum one episode of severe depression, while up to $10 \%$ of young people are affected by a major depressive disorder [Dinas P. et al. 2011].

The change in the levels of monoamines serotonin, norepinephrine (NE) and dopamine (DA) results in depression. $\quad \mathrm{VH}$ is a serotonin-noradrenaline reuptake inhibitor, indicated for the treatment of depression [Zhou Y. et al. 2015]. Serotonin noradrenaline reuptake inhibitors increase the levels of serotonin and noradrenaline in brain by blocking their reuptake by nerves. The patients suffering from depression shows lowered mood, abstinence from pleasure, disturbed food habits, feelings of sorrow, lack of concentration in doing things. These problems culminate into disability or development of suicidal tendencies [Dinas P.etal. 2011].

Central nervous system (CNS) shows barrier property for drug penetration in brain. Blood brain barrier (BBB) and blood cerebrospinal fluid barrier (BCSFB) restricts entry of drug in brain [Abbott $N$ 2010]. It is observed that nearly $100 \%$ of large molecules and $98 \%$ of small molecules does not cross BBB [Tosi G et.al 2008, Bellavance M. 2010]. To overcome these difficulties, use of biocompatible drugloaded polymeric nanoparticles (PNPs) has been proposed [Alexis et al. 2008].

$\mathrm{VH}$ is a highly water soluble, non-tricyclic antidepressant drug. It is serotonin-norepinephrine reuptake inhibitor. It involves $5 \mathrm{HT} 1 \mathrm{a}, 5 \mathrm{HT} 1 \mathrm{~b}$ and $5 \mathrm{HT} 2 \mathrm{a}$ receptors. VH is 5 -HTdopamine activity modulator, dopamine D2 partial agonist and used in treatment of major depressive disorder [Barch D. 2013]. The steady state biological half-lives of venlafaxine 
and its active metabolite o-desmethylvenlafaxine are 5 and $11 \mathrm{~h}$ respectively [Gohel M. 2009].

The low biological half-life $5 \pm 2$ hours coupled with low oral bioavailability $45 \pm 15 \%$ due to its extensive first-pass metabolism requires frequent drug administration to maintain effective plasma concentration of $\mathrm{VH}$. The immediate-release oral formulations have side-effects, including nausea, insomnia, weakness, drowsiness and constipation [Patel H. et al. 2011].

Drugs used in the treatment of depression are selective serotonin reuptake inhibitors, tricyclic antidepressants, monoamine oxidase inhibitors, serotonin norepinephrine reuptake inhibitors [Tripathi K.D. et al. 2009].

Polymeric nanoparticles (PNPs) are solid, colloidal particles prepared from biocompatible and biodegradable polymers in size between 10-1000 $\mathrm{nm}$ where the drug is dissolved, entrapped, encapsulated or attached to a nanoparticle matrix. Depending upon the method of preparation, nanospheres or nanocapsules can be obtained [Anderson J. and Shive M. 1977]. Nanocapsules are systems in which the drug is confined to a cavity surrounded by a unique polymer membrane, while nanospheres are matrix systems in which the drug is physically and uniformly dispersed.

PLGA is a widely used polymer for development of nanoparticles because of biocompatibility and potential to cross the blood brain barrier. [Acharya S. and Sahoo S., 2011]. The polymer has been intensively utilized for drug delivery and to encapsulate both water-soluble and waterinsoluble drugs [Danhier F. et al. 2012].

To overcome the hepatic first pass metabolism of $\mathrm{VH}$, it was envisaged to develop transdermal drug delivery system containing VH loaded polymeric nanoparticles.

Selection of suitable solvent system is the important step in the development of transdermal drug delivery systems. Solvent systems comprising ethanol, propylene glycol and their binary combinations with water in various proportions were studied. The effect of penetration enhancers were studied for their effect on ex-vivo skin permeation of $\mathrm{VH}$ [Panchagnula $\mathrm{R}$ et al. 2001]. It was envisaged to compare the lag time, and flux values of VH, VHNPs with the solvent systems studied in the ex-vivo skin permeation studies.

\section{MATERIALS AND METHOD}

\section{Materials}

VH was obtained as a gratis sample from Amoli Organics Pvt. Ltd. Mumbai, India. Poly (lactic co-glycolic acid) 50:50 (Molecular weight.24000-38000 Da) was obtained as a gratis sample from Evonik India Pvt. Ltd. Mumbai, India. Tween 80 was obtained from Loba Chemie Pvt. Ltd, India. Ethylene vinyl acetate copolymer (EVAC), dibutyl phthalate, ethanol, propylene glycol, cineole, limonene, and menthol were procured from Merck India Pvt. Ltd, India. Purified water was obtained from Milli-Q water purification system.

\section{Method}

\section{Preparation of polymeric nanoparticles of $\mathrm{VH}$}

Polymeric nanoparticles of VH with PLGA polymer were prepared by double emulsion solvent evaporation method. The drug, VH was dissolved in distilled water and poly(lactic co-glycolic acid) was dissolved in dichloromethane. A w/o type emulsion was prepared using various concentrations of drug: polymer ratio (Table 1). An accurately weighed amount of VH and PLGA polymer were dissolved in $2 \mathrm{~mL}$ distilled water and $6 \mathrm{~mL}$ dichloromethane respectively to form $\mathrm{w} / \mathrm{o}$ type primary emulsion [Bilati U. et al. 2005, Vandervoort J. et al. 2002]..

The primary emulsion was dropwise added using syringe into aqueous phase $(\mathrm{w})$ containing tween-80 surfactant solutions. The resulting w/o/w type secondary formed was kept overnight on continuous magnetic stirring at room temperature for complete evaporation of dichloromethane. The secondary emulsion was homogenized using a highspeed homogenizer (IKA Ultra Turrex T18, Germany) at $12,000 \mathrm{rpm}$ speed for $15 \mathrm{~min}$ followed by probe sonication (Sonics Vibra Cell ${ }^{\mathrm{TM}}$ ) at $80 \%$ amplitude for $10 \mathrm{~min}$.

The polymeric nanoparticles were recovered by centrifugation using a refrigerated centrifuge at 20,000 rpm for 1 hour at $4{ }^{\circ} \mathrm{C}$. The supernatant liquids were discarded and washed thrice with distilled water to remove the adsorbed polymer and drug. The pellets formed of nanoparticles was obtained after centrifugation (Remi C24 Plus). To the formed pellet, a $5(\% \mathrm{w} / \mathrm{v})$ solution of mannitol was added as cryoprotectant and filled in glass vials. The vials were freeze dried at $(-) 40{ }^{\circ} \mathrm{C}$ and $750 \mathrm{~mm} / \mathrm{Hg}$ vacuum pressure out for $72 \mathrm{~h}$. The freeze-dried powder product was stored in refrigerator in airtight glass container.

Table 1 Formulation of VH loaded polymeric PLGA nanoparticles

\begin{tabular}{|c|c|c|c|c|c|}
\hline \multirow{3}{*}{$\begin{array}{l}\text { Formulation } \\
\text { code }\end{array}$} & \multirow{2}{*}{$\begin{array}{l}\text { Dose of drug } \\
(\mathrm{VH})\end{array}$} & \multirow{2}{*}{$\begin{array}{l}\text { Solvents } \\
\text { Water: DCM } \\
\text { in 1:3 ratio }\end{array}$} & Factor 1 & Factor 2 & \multirow{2}{*}{$\begin{array}{l}\text { Distilled } \\
\text { water (q.s.) }\end{array}$} \\
\hline & & & $\begin{array}{l}\text { A: Concentration of } \\
\text { PLGA polymer }\end{array}$ & $\begin{array}{l}\text { B:Concentration of } \\
\text { surfactant tween-80 }\end{array}$ & \\
\hline & $\mathrm{mg}$ & $\mathrm{mL}$ & $\mathrm{mg}$ & $\% \mathrm{v} / \mathrm{v}$ & $\mathrm{mL}$ \\
\hline $\mathrm{F} 1$ & 37.5 & 2 & 37.5 & 2.0 & 100 \\
\hline $\mathrm{F} 2$ & 37.5 & 2 & 37.5 & 0.5 & 100 \\
\hline F3 & 37.5 & 2 & 75 & 2.0 & 100 \\
\hline $\mathrm{F} 4$ & 37.5 & 2 & 75 & 1.0 & 100 \\
\hline F5 & 37.5 & 2 & 75 & 0.5 & 100 \\
\hline F6 & 37.5 & 2 & 112.5 & 0.5 & 100 \\
\hline F7 & 37.5 & 2 & 37.5 & 1.0 & 100 \\
\hline F8 & 37.5 & 2 & 112.5 & 1.0 & 100 \\
\hline F9 & 37.5 & 2 & 112.5 & 2.0 & 100 \\
\hline
\end{tabular}




\section{Experimental Design}

A full factorial design for two factors at three levels each was selected to optimize response of variables. The two factors, PLGA sustained release polymer (mg) and tween $80(\% \mathrm{v} / \mathrm{v})$ used were varied and the factor levels were suitably coded. The particle size, polydispersity index, zeta potential and $\%$ entrapment efficiency were taken as the response variables. In the design, the two factors were evaluated each at three levels and experimental trials were performed for possible combinations. All other formulation variables and processing variables were kept constant throughout the studies.

The formulae were developed as 9 sets varying the variables following $3^{2}$ full factorial design (3 levels) using Design expert software. Dependent variables were $Y 1=$ Particle size $\mathrm{Y} 2=$ Polydispersity index, $\mathrm{Y} 3=$ Zeta potential and $\mathrm{Y} 4=\%$ Entrapment efficiency. The effect of two independent variables PLGA (X1) and Tween-80 (X2) on the responses (Y1, Y2, Y3 and Y4) were observed. The levels of all other ingredients in the formulation were fixed.

\section{Characterization of lyophilized VH loaded polymeric PLGA Nanoparticles}

Determination of particle size, polydispersity index (PDI) and zeta potential

Lyophilized dried powders of nanoparticles were dispersed in distilled water and were kept in an ultrasonicator for 40 seconds. The mean particle size ( $\mathrm{z}$ average), zeta potential, and polydispersity index (PDI) of aqueous dispersion of $\mathrm{VH}$ loaded PPNPs were measured by a dynamic light scattering method using a Zetasizer Nano ZS-90 (Malvern Instruments, Worcestershire, UK). Each value recited was the average of determinations on three independent samples of different batches of each formulation. If PDI value is closer to 0 , it indicates narrow size distribution of the particles. PDI of optimized dispersion was below 0.5 which indicated prepared dispersion is monodisperse and will remain stable [Katara R. et.al. 2017].

\section{Determination of percent entrapment efficiency and percent drug loading}

VH loaded NPs and naive NPs were obtained as pellets after centrifugation at $18000 \mathrm{rpm}$ for $60 \mathrm{~min}$ at $4{ }^{\circ} \mathrm{C}$. The absorbance of the clear supernatant obtained after centrifugation of dispersion of drug loaded NPs was analyzed in UV spectrophotometer (SHIMADZU 1800) at $\lambda \max 226 \mathrm{~nm}$ against the supernatant obtained from the dispersion of naive NPs and was used as blank. The clear supernatant also contained the free drug which was obtained by washing of the NPs, in the dispersion with deionized water.

The drug entrapment efficiency was determined using the equation 1 [Lopez E. et al., 2016].

Total amount of VH added - Free VH in supernatant liquid

$\% \mathrm{EE}=$ $x 100$

Total amount of VH added

\section{Polymer drug interaction studies of lyophilized nanoparticles}

The polymer drug interaction studies of lyophilized nanoparticles were performed using FT-IR spectroscopy, differential scanning calorimetry and x-ray diffraction spectroscopy and scanning electron microscopy studies.

\section{FT-IR spectroscopy}

FT-IR spectrum of VH, PLGA polymer and optimized formulation F9 was measured in solid state as potassium bromide mixture. (FTIR 8300 Shimadzu, Tokyo, Japan). The samples were previously ground and mixed thoroughly with potassium bromide, an infrared transparent matrix at 1:100 (Sample: KBr) ratio, respectively. The spectrum was recorded in the range $4000-400 \mathrm{~cm}^{-1}$ [Katara R. et.al. 2017].

\section{Differential scanning calorimetry (DSC)}

The sample of VH, PLGA polymer and lyophilized nanoparticles of optimized formulation F9 was kept in desiccator for $24 \mathrm{~h}$ before thermal analysis. An accurately weighed sample, $5 \mathrm{mg}$ was hermetically sealed in aluminium crucible and DSC analysis was performed using DSC TA-60 (Shimadzu, Tokyo, Japan) calorimeter heated at constant rate of $10{ }^{\circ} \mathrm{C} / \mathrm{min}$. over a temperature range 40 to $400{ }^{\circ} \mathrm{C}$. An inert atmosphere was maintained by purging nitrogen gas at a flow rate of $50 \mathrm{~mL} / \mathrm{min}$. An empty aluminium pan was used as a reference [Katara R. et.al. 2017].

$\mathrm{X}$-ray diffraction (X-RD) spectroscopy
X-ray diffraction spectrum of VH, PLGA and lyophilized nanoparticles of optimized formulation F9 was recorded in diffractometer (Rigaker Geigerflex, Japan) using $\mathrm{Cu}-\mathrm{K} \alpha$ line as source of radiation at a voltage of $35 \mathrm{Kv}$ and current 25 $\mathrm{mA}$. The sample was measured in an angle $2 \theta$ range between $3-80^{\circ}$ and 0.0053 step size [Katara R. et al. 2017, Sawant et al. 2011].

\section{Scanning electron microscopic (SEM) study}

Shape and surface morphology of VH PPNPs was visualized by scanning electron microscopy (LEO-430 Cambridge and U.K). Samples were prepared by lightly sprinkling nanoparticles on a double adhesive tape on an aluminum stub. The stubs were coated with gold to a thickness of 200 to $500 \mathrm{~A}^{\circ}$ under an argon atmosphere using gold sputter module in a high vacuum evaporator. The samples were then randomly scanned and photomicrographs were recorded at different magnifications with SEM [Gulati N. et al. 2014].

\section{Ex-vivo skin permeation studies}

For preparation of whole skin, the animal was sacrificed by excess inhalation of diethyl ether anesthetic agent. The abdominal skin of animal was shaved with the help of animal hair remover or clipper in the direction of tail to head without causing damage to skin. The shaved skin was excised with the help of surgical blade (size 24) fitted in a surgical blade holder (size 4). The adhered tissues to the dermis were removed with the help of cotton swab moistened with isopropyl alcohol. The skin was washed with distilled water, wrapped in aluminum foil and stored in freezer at $(-) 20{ }^{\circ} \mathrm{C}$ until further use. The skin was thawed to room temperature. 
It was kept in thermostatic shaker bath at $37 \pm 1$ oC temperature for $1 \mathrm{~h}$. The receptor fluid phosphate buffer $\mathrm{pH}$ 7.4 containing $0.01 \%$ sodium azide was added in the receptor medium to retard microbial growth and equilibrated to bring it to $37 \pm 1{ }^{\circ} \mathrm{C}$ temperature [Panchagnula R. et al. 2001].

The skin was cut into circular pieces to a size of external circumference of donor compartment and mounted on diffusion cell assembly, keeping stratum corneum side towards donor compartment and equilibrated for $1 \mathrm{~h}$. Depending on drug solubility of $\mathrm{VH}$, the binary combination of ethanol, propylene glycol and their binary combinations with water in various proportions were used as solvent system for ex-vivo skin permeation studies as shown in table 2. In the $2 \mathrm{~mL}$ solvent system, $37.5 \mathrm{mg}$ was dissolved and added in donor phase compartment of diffusion assembly. Based on the flux values, optimized solvent system was selected showing highest flux as compared to other binary solvent systems studied. The effect of penetration enhancer, cineole, limonene, menthol were studied by incorporating them individually in the optimized binary combination of solvent system used in ex- vivo permeation studies. From the receptor compartment, $1 \mathrm{~mL}$ volume was withdrawn at 0,1 , $2,4,6,8,10,12,16,20,24,36$ and $48 \mathrm{~h}$ and replaced with equal volume of fresh receptor phase every time to determine the amount of drug permeated through the skin.

Cartesian plots were made taking time in hours on $\mathrm{x}$-axis and cumulative amount of drug permeated in receptor fluid on yaxis The lag time, flux, permeability, and enhancement ratio were calculated. Flux values $\left(\mu \mathrm{g} / \mathrm{cm}^{2} / \mathrm{h}\right)$ were calculated from the slopes of the steady states of above plots. Lag times were calculated from the intercepts of extrapolated steady state flux to $\mathrm{x}$-axis. Flux, Permeability coefficient and enhancement ratio were calculated using equation 2 .

A) The flux $\left(\mathrm{Jss}_{\mathrm{ss}}\right)\left(\mathrm{mg} / \mathrm{cm}^{2} / \mathrm{h}\right)$ was calculated from the slope of the plot of the cumulative amount of drug permeated per $\mathrm{cm}^{2}$ of skin at steady state against time using linear regression analysis.

$\mathrm{J}_{\mathrm{ss}}=(\mathrm{dy} / \mathrm{dx})_{\mathrm{ss}} \times 1 / \mathrm{A}$

Where, $(\mathrm{dy} / \mathrm{dx})_{\mathrm{ss}}=$ Steady state slope and

$A=$ Effective diffusion area

B) Permeability coefficient (P) were determined by using equation 3 [Krishnaiah Y.2008].

Steady State Flux (J)

Permeability $(\mathrm{P})=$

Concentration of drug in donor solution (C)

C) Enhancement ratio (ER) were determined by using following equation [Krishnaiah Y.2008].

Flux of drug with penetration enhancer

Enhancement ratio $(\mathrm{ER})=$

Flux of drug without penetration enhancer

Table 2 Solvent systems, permeation enhancers for ex-vivo skin permeation studies of VH and polymeric nanoparticles of VH

\begin{tabular}{|c|c|c|c|c|c|c|c|c|}
\hline $\begin{array}{l}\text { Sr. } \\
\text { No. }\end{array}$ & $\mathrm{FC}$ & Solvent system & $\begin{array}{l}\text { Dose of VH } \\
(\mathrm{mg})\end{array}$ & $\begin{array}{l}\text { PG } \\
(\mathrm{mL})\end{array}$ & $\begin{array}{l}\text { EtoH } \\
(\mathrm{mL})\end{array}$ & $\begin{array}{l}\text { DW } \\
(\mathrm{mL})\end{array}$ & $\begin{array}{l}\text { PPNPs } \\
\text { VH } \\
(\mathrm{mL})\end{array}$ & PE (\%) \\
\hline 1 & W & Water (Control) & 37.5 & & & 2.0 & & \\
\hline 2 & NPs & Nanoparticles & 37.5 & & & & 2.0 & \\
\hline 3 & V1 & $33 \%$ EtoH in DW & 37.5 & & 0.7 & 1.3 & & \\
\hline 4 & V2 & $50 \%$ EtoH in DW & 37.5 & & 1.0 & 1.0 & & \\
\hline 5 & V3 & $66 \%$ EtoH in DW & 37.5 & & 1.3 & 0.7 & & \\
\hline 6 & V4 & $100 \%$ EtoH & 37.5 & & 2.0 & & & \\
\hline 7 & V5 & $33 \% \mathrm{PG}$ in DW & 37.5 & 0.7 & & 1.3 & & \\
\hline 8 & V6 & $50 \%$ PG in DW & 37.5 & 1.0 & & 1.0 & & \\
\hline 9 & V7 & $66 \%$ PG in DW & 37.5 & 1.3 & & 0.7 & & \\
\hline 10 & V8 & $100 \% \mathrm{PG}$ & 37.5 & 2.0 & & & & \\
\hline 11 & V9 & 33\% PG in EtoH & 37.5 & 0.7 & 1.3 & & & \\
\hline 12 & V10 & $50 \%$ PG in EtoH & 37.5 & 1.0 & 1.0 & & & \\
\hline 13 & V11 & $66 \%$ PG in EtoH & 37.5 & 1.3 & 0.7 & & & \\
\hline 14 & V12 & $5 \%$ Cineole (50\% PG in EtoH) & 37.5 & & & & & $5 \%$ \\
\hline 15 & V13 & 5\% Limonene (50\% PG in EtoH) & 37.5 & & & & & $5 \%$ \\
\hline 16 & V14 & 5\% Menthol (50\% PG in EtoH) & 37.5 & & & & & $5 \%$ \\
\hline
\end{tabular}

FC- Formulation code, VH- venlafaxine hydrochloride, PG- propylene glycol, EtOH- Ethanol, DW- Distilled water, PNPs VHpolymeric PLGA nanoparticles comprising VH, PE- Permeation enhancers 


\section{RESULTS AND DISCUSSION}

\section{Experimental design}

The formulations were prepared as 9 sets using two variables following $3^{2}$ factorial designs. VH loaded polymeric PLGA NPs were prepared by double emulsion solvent evaporation technique. The optimized formulations selected by the design were prepared and the parameters were compared to the expected values. The results are shown in table 3. For systematic investigation of the factors, a full factorial design was employed.

Table 3 Optimization of formulation by using $3^{2}$ full factorial design

\begin{tabular}{|c|c|c|c|c|c|c|c|c|}
\hline \multirow[t]{2}{*}{$\begin{array}{l}\text { Formulation } \\
\text { code }\end{array}$} & \multirow{2}{*}{$\begin{array}{l}\text { Dose } \\
\text { of } \\
\mathrm{VH}\end{array}$} & \multirow{2}{*}{$\begin{array}{c}\text { Solvents } \\
\text { DW: DCM } \\
(1: 3) \text { ratio }\end{array}$} & Factor 1 & Factor 2 & Response 1 & Response 2 & $\begin{array}{c}\text { Response } \\
3\end{array}$ & Response 4 \\
\hline & & & $\begin{array}{c}\text { A: } \\
\text { Concentration. } \\
\text { of PLGA } \\
\text { polymer }\end{array}$ & $\begin{array}{c}\text { B: } \\
\text { Concentration } \\
\text { of Tween-80 } \\
\text { surfactant }\end{array}$ & Particle size & PDI & $\begin{array}{c}\text { Zeta } \\
\text { potential }\end{array}$ & $\begin{array}{c}\text { Entrapment } \\
\text { efficiency }\end{array}$ \\
\hline
\end{tabular}

\begin{tabular}{ccccccccc} 
& $\mathrm{mg}$ & $\mathrm{mL}$ & $\mathrm{mg}$ & $\% \mathrm{v} / \mathrm{v}$ & $\mathrm{nm}$ & - & $\mathrm{mV}$ & $\%$ \\
\hline F1 & 37.5 & 2 & 37.5 & 2.0 & $128.4 \pm 2.25$ & $0.181 \pm 0.05$ & $-6.8 \pm 0.26$ & $36 \pm 3.12$ \\
\hline F2 & 37.5 & 2 & 37.5 & 0.5 & $78.2 \pm 1.96$ & $0.103 \pm 0.03$ & $-12.4 \pm 0.41$ & $33 \pm 1.95$ \\
\hline F3 & 37.5 & 2 & 75 & 2.0 & $214.6 \pm 3.22$ & $0.331 \pm 0.07$ & $-15.2 \pm 0.32$ & $45 \pm .3 .05$ \\
\hline F4 & 37.5 & 2 & 75 & 1.0 & $188.1 \pm 2.86$ & $0.276 \pm 0.06$ & $-14.3 \pm 0.54$ & $43 \pm 2.68$ \\
\hline F5 & 37.5 & 2 & 75 & 0.5 & $163.8 \pm 2.94$ & $0.243 \pm 0.03$ & $-12.7 \pm 0.37$ & $40 \pm 2.08$ \\
\hline F6 & 37.5 & 2 & 112.5 & 0.5 & $192.6 \pm 3.18$ & $0.291 \pm 0.09$ & $-10.2 \pm 0.30$ & $47 \pm 1.12$ \\
\hline F7 & 37.5 & 2 & 37.5 & 1.0 & $97.6 \pm 1.37$ & $0.137 \pm 0.05$ & $-9.8 \pm 0.62$ & $31 \pm 1.98$ \\
\hline F8 & 37.5 & 2 & 112.5 & 1.0 & $201.3 \pm 3.42$ & $0.238 \pm 0.08$ & $-10.5 \pm 0.29$ & $51 \pm 2.14$ \\
\hline F9 & $\mathbf{3 7 . 5}$ & $\mathbf{2}$ & $\mathbf{1 1 2 . 5}$ & $\mathbf{2 . 0}$ & $\mathbf{1 7 5 . 4}$ & $\mathbf{0 . 1 0 9}$ & $\mathbf{- 2 4 . 0}$ & $\mathbf{5 6} \pm \mathbf{3 . 5 6}$ \\
& & & & & $\mathbf{\pm 1 . 4 8}$ & $\mathbf{\pm 0 . 0 6}$ & $\pm \mathbf{0 . 3 3}$ & \\
\hline
\end{tabular}

Data were expressed as mean \pm SD $(n=3)$

The effect on particle size (Y1) was observed to be significant by ANOVA and the polynomial equation was found to follow equation 5 .

$\mathrm{Y}_{1}=218.586+42.1048 * \mathrm{~A}+11.8881 * \mathrm{~B}-18.7071 * \mathrm{AB}-$ $65.225 * \mathrm{~A}^{\wedge} 2-9.175 * \mathrm{~B}^{\wedge} 2$

The terms A and B indicate concentrations of polymers PLGA and tween 80 respectively. As shown in equation 5, the positive sign with terms $A$ and $B$ indicated directly proportional relationship between concentration of polymers and particles size. As the concentrations of both polymers and surfactant were increased, the particles size was found to be increased. For response $\mathrm{Y} 1$ as shown in table 4, the coefficient of determination value $\left(\mathrm{R}^{2}\right)$ was found to be 0.9880 indicating a good fit agreement between concentrations of polymers and particle size. The 3D surface response plot of particle size and its contour plot are shown in figure $1(\mathrm{~A})$ and $(\mathrm{B})$ respectively.

The effect on polydispersity index (Y2) was observed to be significant by ANOVA and the polynomial equation was found to follow equation 6 .

$\mathrm{Y}_{2}=0.314189+0.0283656 * \mathrm{~A}-0.0104677 * \mathrm{~B}-0.0702092 *$ $\mathrm{AB}-0.13375 * \mathrm{~A}^{\wedge} 2-0.00725 * \mathrm{~B}^{\wedge} 2$

The term A indicates concentration of PLGA whereas, term B indicates concentration of tween 80 . By analyzing the equation, the positive response was observed for polydispersity index with PLGA. In case of tween 80 , a negative response indicating the decreased polydispersity index was observed with decreased in tween 80 concentration. The coefficient of determination was found to be value $\left(R^{2}\right) 0.9424$ indicated the best fit agreement between effect of polymers on polydispersity index. The 3D surface response plot of polydispersity index and its contour plot are shown in figures 1 (C) and (D) respectively.
The effect on zeta potential (Y3) was observed to be significant by ANOVA and the polynomial equation was found to follow equation 7 .

$\mathrm{Y}_{3}=-14.4046-3.17049 * \mathrm{~A}-2.33716 * \mathrm{~B}-4.98444 * \mathrm{AB}+$ $2.9875 * \mathrm{~A}^{\wedge} 2-1.6 * \mathrm{~B}^{\wedge} 2$

The term A indicates concentration of PLGA whereas term $B$ indicates concentration of tween 80. By analyzing the equation, a negative response was observed for zeta potential with increasing concentration of tween 80 and PLGA. The coefficient of determination $\left(\mathrm{R}^{2}\right)$ was found to be 0.9524 indicating the good fit agreement between effects of polymers on particle size, PDI, zeta potential and entrapment efficiency. The 3D surface response plot of particle size, PDI, zeta potential and entrapment efficiency and its contour plot are shown in figures 1 (E) and (F) respectively.

The effect on entrapment efficiency (Y4) was observed to be significant by ANOVA and the polynomial equation was found to follow equation 8 .

$\mathrm{Y}_{4}=46.2385+9.14668 * \mathrm{~A}+2.98002 * \mathrm{~B}+1.32015 * \mathrm{AB}-$ $3.75 * \mathrm{~A}^{\wedge} 2+0.25 * \mathrm{~B}^{\wedge} 2$

The term A indicates concentration of PLGA whereas term B indicates concentration of tween 80 . By analysing the equation, polymer and surfactant concentration were found to increase entrapment efficiency. The coefficient of determination $\left(\mathrm{R}^{2}\right)$ was found to be 0.9614 indicating the good fit agreement between effects of polymers on particle size, PDI, zeta potential and entrapment efficiency. The 3D surface response plot of particle size, PDI, zeta potential and entrapment efficiency and its contour plot are shown in figures $1(\mathrm{G})$ and $(\mathrm{H})$ respectively.

The p-values for particle size, PDI, Zeta potential and entrapment efficiency were found to be $0.004,0.04$ and 0.03 and 0.005 respectively. Thus, the P-values were found to be significant. 

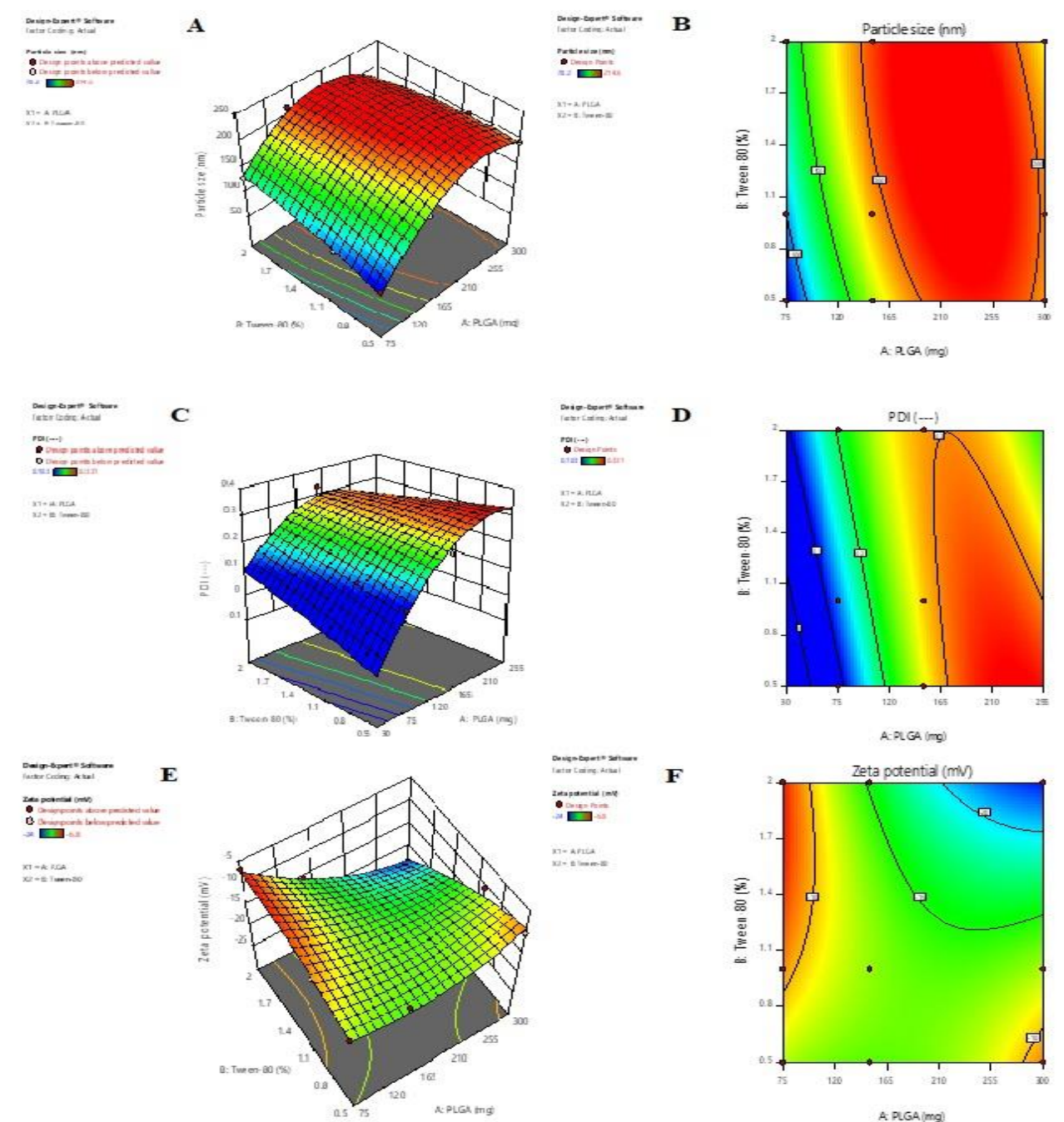

$\mathbf{F}$
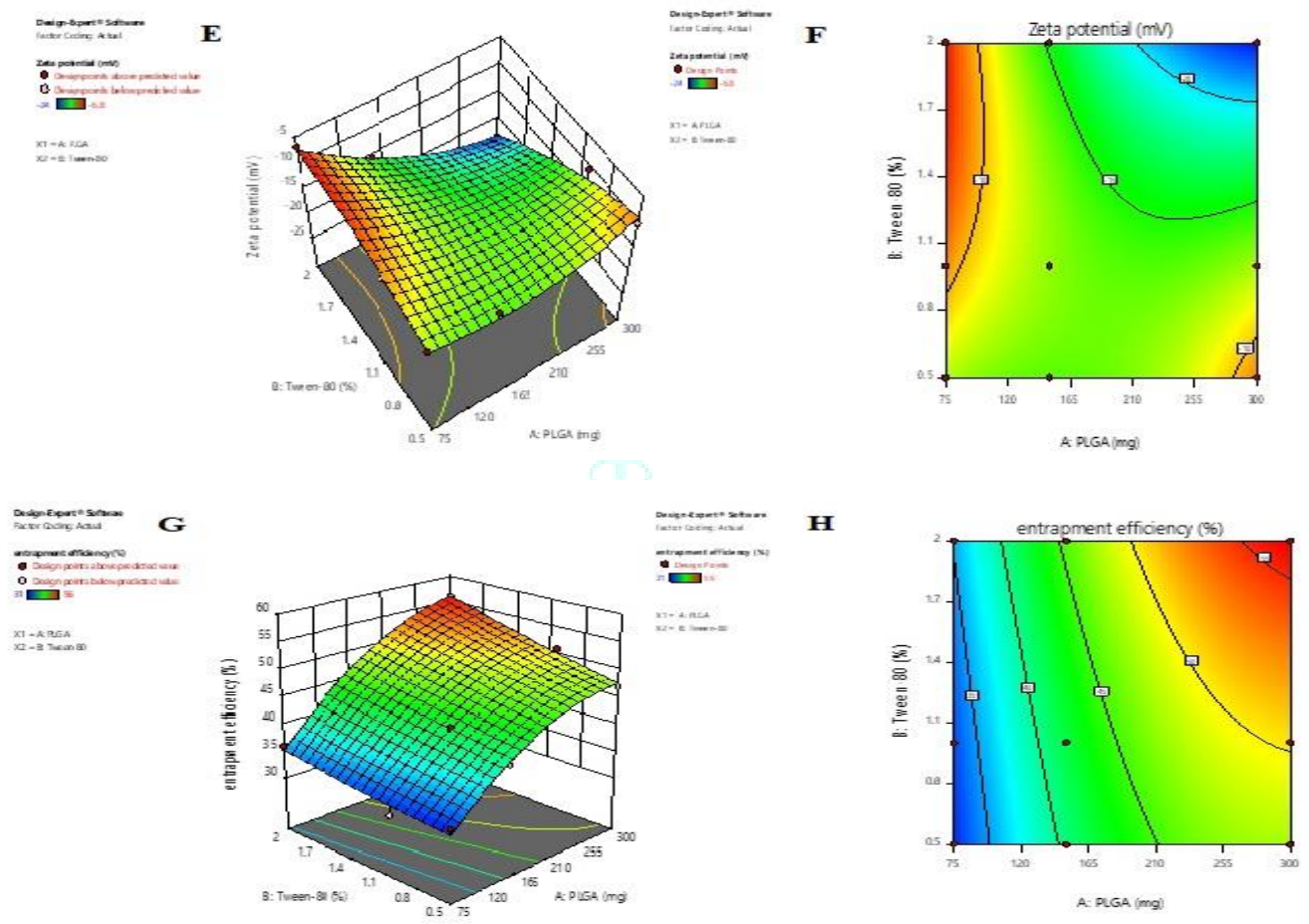

Fig. 1 3D response surface plot and contour plot of particle size, PDI, zeta potential and \% EE of VH loaded PNPs

(A) 3D response surface plot of particle size VH loaded PNPs $\begin{array}{ll}\text { (B) Contour plot of particle size VH loaded PNPs } & \text { (C) } 3 \mathrm{D}\end{array}$ response surface plot of PDI VH loaded PNPs (D) Contour plot of PDI VH loaded PNPs (E) 3D response surface plot of zeta potential VH loaded PNPs (F) Contour plot of zeta potential VH loaded PNPs (G) 3D response surface plot of \% EE VH loaded PNPs (H) Contour plot of \%EE VH loaded PNPs

\section{Characterization of VH loaded PNPs}

Determination of particle size, polydispersity index (PDI) and zeta potential

The particle size and PDI of the VH loaded polymeric PLGA nanoparticles are important characters in determining the capability of the particles to cross the BBB. The particle size and PDI of formulations (F1-F9) were obtained using Zetasizer Nano ZS 90 and the results are depicted in table 4 and particle size and PDI of optimized formulation F9 is shown in Fig. 2.

Table 4 Evaluations of particle size and PDI of formulations F1-F9

\begin{tabular}{llll}
\hline $\begin{array}{l}\text { Sr. } \\
\text { No. }\end{array}$ & Formulations & Particle Size $(\mathrm{nm})$ & PDI \\
\hline 1 & F1 & $128.4 \pm 2.25$ & $0.181 \pm 0.05$ \\
\hline 2 & F2 & $78.2 \pm 1.96$ & $0.103 \pm 0.03$ \\
\hline 3 & F3 & $214.6 \pm 3.22$ & $0.331 \pm 0.07$ \\
\hline 4 & F4 & $188.1 \pm 2.86$ & $0.276 \pm 0.06$ \\
\hline 5 & F5 & $163.8 \pm 2.94$ & $0.243 \pm 0.03$ \\
\hline 6 & F6 & $192.6 \pm 3.18$ & $0.291 \pm 0.09$ \\
\hline 7 & F7 & $97.6 \pm 1.37$ & $0.137 \pm 0.05$ \\
\hline 8 & F8 & $201.3 \pm 3.42$ & $0.238 \pm 0.08$ \\
\hline $\mathbf{9}$ & F9 & $\mathbf{1 7 5 . 4 \pm 1 . 4 8}$ & $\mathbf{0 . 1 0 9} \pm \mathbf{0 . 0 6}$ \\
\hline \multicolumn{4}{c}{ Data were expressed as mean \pm SD $(\mathrm{n}=3)$}
\end{tabular}




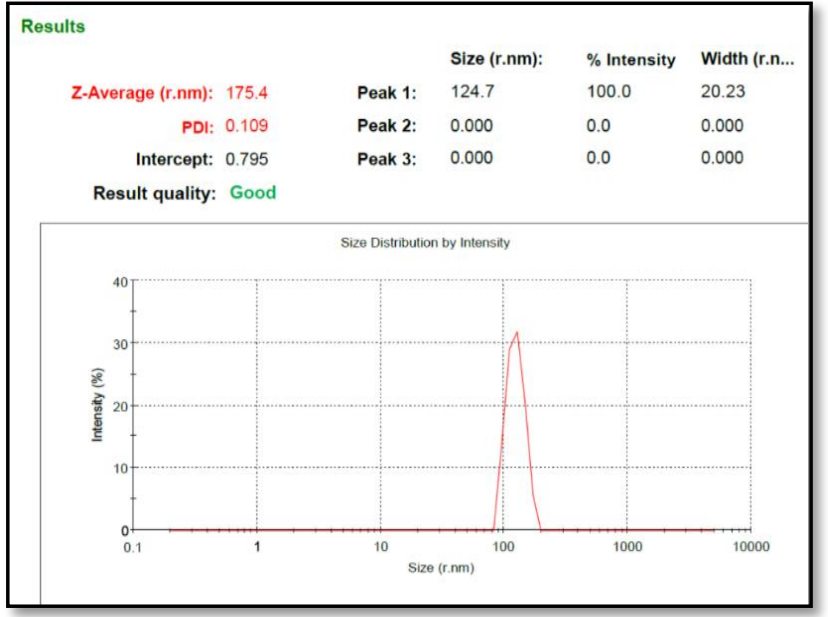

Fig. 2 Particle size and PDI of optimized formulation F9

\section{Determination of zeta potential}

The zeta potential of the polymeric nanoparticles is important to determine the stability and uptake mechanism of the particles inside the body. The zeta potential of the formulations F1-F9 is shown in table 5 and zeta potential of optimized formulation F9 is shown in fig. 3.

Table 5 Evaluations of Zeta potential (F1-F9)

\begin{tabular}{lll}
\hline Sr. No. & Formulation code & Zeta potential $(\mathrm{mV})$ \\
\hline 1 & F1 & $-6.8 \pm 0.26$ \\
\hline 2 & F2 & $-12.4 \pm 0.41$ \\
\hline 3 & F3 & $-15.2 \pm 0.32$ \\
\hline 4 & F4 & $-14.3 \pm 0.54$ \\
\hline 5 & F5 & $-12.7 \pm 0.37$ \\
\hline 6 & F6 & $-10.2 \pm 0.30$ \\
\hline 7 & F7 & $-9.8 \pm 0.62$ \\
\hline 8 & F8 & $-10.5 \pm 0.29$ \\
\hline $\mathbf{9}$ & F9 & $\mathbf{- 2 4 . 0 \pm 0 . 3 3}$ \\
\hline
\end{tabular}

Data were expressed as mean \pm SD $(n=3)$

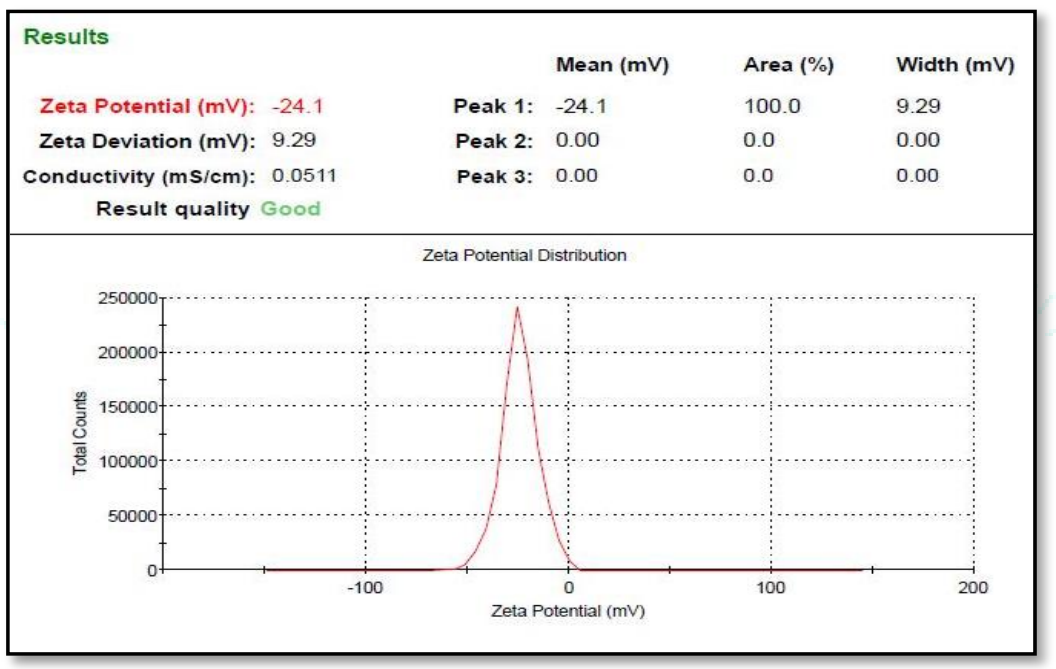

Fig. 3 Zeta potential of optimized formulation F9

\section{Determination of percent entrapment efficiency}

The results of percent entrapment efficiency and percent drug loading of formulations F1-F9 are shown in table 6.

Table 6 Formulations of percent entrapment efficiency of formulations F1-F9

\begin{tabular}{lll}
\hline Sr. No. & $\begin{array}{l}\text { Formulation } \\
\text { code }\end{array}$ & $\begin{array}{l}\text { \% Entrapment } \\
\text { efficiency }\end{array}$ \\
\hline 1 & F1 & $36 \pm 3.12$ \\
\hline 2 & F2 & $33 \pm 1.95$ \\
\hline 3 & F3 & $45 \pm .3 .05$ \\
\hline 4 & F4 & $43 \pm 2.68$ \\
\hline 5 & F5 & $40 \pm 2.08$ \\
\hline 6 & F6 & $47 \pm 1.12$ \\
\hline 7 & F7 & $31 \pm 1.98$ \\
\hline 8 & F8 & $51 \pm 2.14$ \\
\hline $\mathbf{9}$ & F9 & $\mathbf{5 6} \pm \mathbf{3 . 5 6}$ \\
\hline
\end{tabular}

\section{FT-IR spectroscopy}

The FT-IR spectra of VH, PLGA polymer and VH loaded polymeric PLGA nanoparticles (fig. 4 (A), (B), (C) respectively) were recorded from $400-4000 \mathrm{~cm}^{-1}$, The $\mathrm{KBr}$ press plate technique was used to prepare sample. The ratio of VH to PLGA polymers was kept at 1:100 for preparation of sample. The FT-IR spectrum of VH shown peaks $1244.11 \mathrm{~cm}^{-}$ 1 (C-O-C stretching), $1450 \mathrm{~cm}^{-1}$ (- $\mathrm{CH}_{3}$ bend), $1375 \mathrm{~cm}^{-1}\left(-\mathrm{CH}_{3}\right.$ bend,) 1465 ( $-\mathrm{CH}_{2}$ bend), $1600 \mathrm{~cm}^{-1}$ ( $\mathrm{C}=\mathrm{C}$ aromatic stretch), $2835.41 \mathrm{~cm}^{-1}$ (cyclic aliphatic - $\mathrm{CH}$ stretch), $3328.3 \mathrm{~cm}^{-1}(-\mathrm{OH}$ alcohol H-bonded). FT-IR spectrum of PLGA polymer shown the peaks $2358.98 \mathrm{~cm}^{-1}(\mathrm{C}=0), 1749.47 \mathrm{~cm}^{-1}(\mathrm{C}=0), 1457.25$ $\mathrm{cm}^{-1} \quad$ (C-O), $1273.04 \mathrm{~cm}^{-1} \quad(\mathrm{C}-\mathrm{C}), 2876.88 \mathrm{~cm}^{-1} \quad\left(-\mathrm{CH}_{3}\right.$ symmetric), $2946.32 \mathrm{~cm}^{-1}$ (- $\mathrm{CH}_{3}$ Asymmetric), $3647.45 \mathrm{~cm}^{-1}$ (O-H), $2876.88 \mathrm{~cm}^{-1}$ (C-H symmetric), $2946.32 \mathrm{~cm}^{-1}$ (C-H Asymmetric). The FT-IR spectrum of VH loaded polymeric PLGA NPs shown the peaks $2946.32 \mathrm{~cm}^{-1}$ (C-H asymmetric stretch), $1448.57 \mathrm{~cm}^{-1}\left(-\mathrm{CH}_{3}\right.$ bend). 


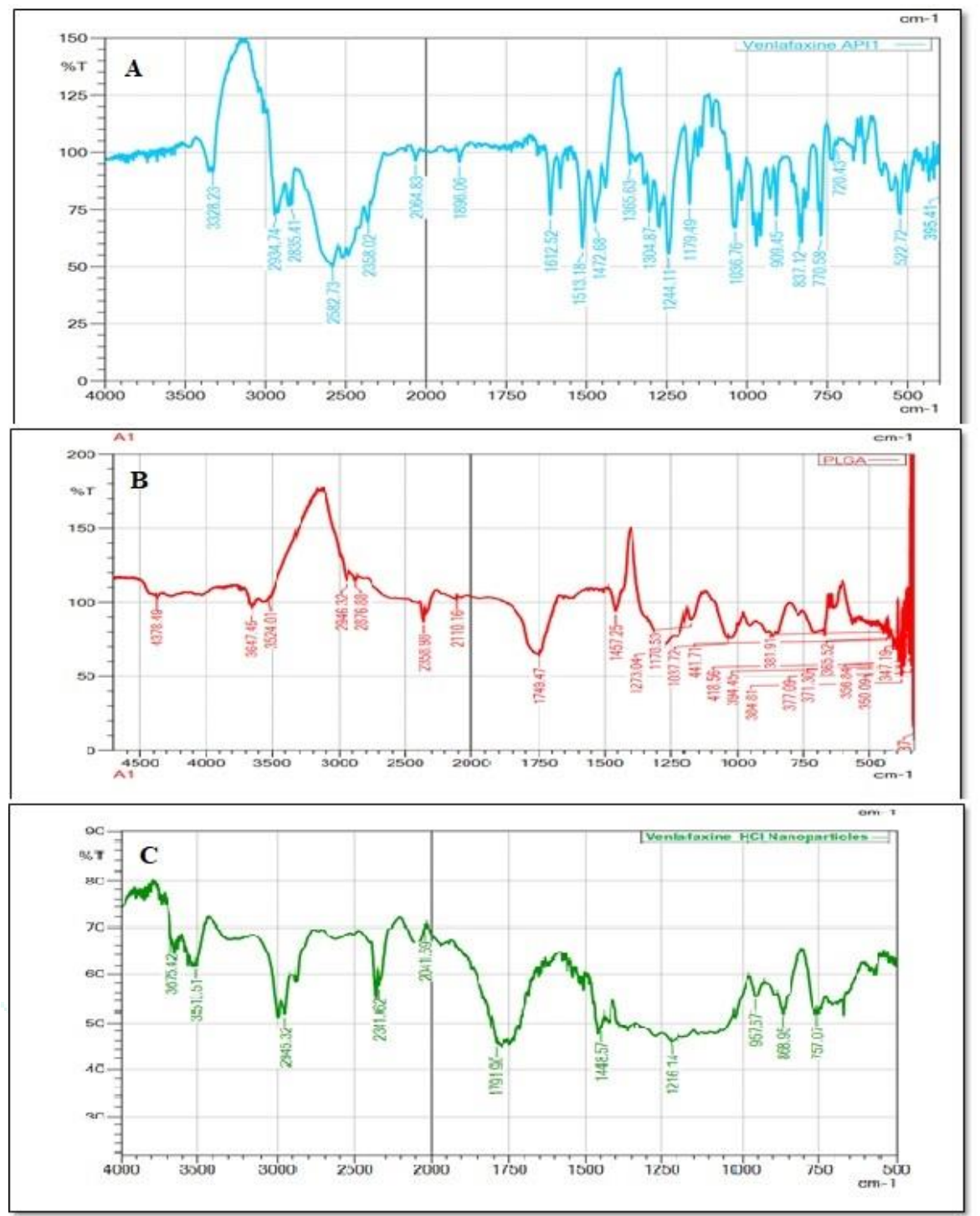

Fig. 4 FT-IR spectrum of VH, PLGA and VH loaded PPNPs(A) FT-IR spectrum of VH (B) FT-IR spectrum of PLGA (C) FT-IR spectrum of VH loaded PNPs

\section{Differential scanning colorimetry}

The DSC thermogram of VH, PLGA and VH loaded PPNPs (shown in fig. 5 (A), (B), (C) respectively) were recorded SHIMADZU DSC instrument. The heating rate was kept at 5 ${ }^{\circ} \mathrm{C} / \mathrm{min}$. up to $300{ }^{\circ} \mathrm{C}$. The DSC thermogram of VH shown the onset of melting process at $210.64{ }^{\circ} \mathrm{C}$ and endset at 214.32 ${ }^{\circ} \mathrm{C}$. A sharp melting peak was observed at $211.97{ }^{\circ} \mathrm{C}$ which was found to be near to the reported value $215-217^{\circ} \mathrm{C}$ as melting point range of $\mathrm{VH}$. The enthalpy for the endothermic transition was found to be (-) $64.90 \mathrm{~J} / \mathrm{g}$. PLGA polymer shown the onset of melting point at $43.6{ }^{\circ} \mathrm{C}$ and end set at $48.39{ }^{\circ} \mathrm{C}$ with glass transition temperature at $46.40{ }^{\circ} \mathrm{C}$ which was found to be as per the reported value of glass transition temperature for PLGA at $44-48^{\circ} \mathrm{C}$. The VH loaded PNPs were subjected to DSC analysis. It showed the onset at $42.21{ }^{\circ} \mathrm{C}$ and endset at $46.94{ }^{\circ} \mathrm{C}$ with an endothermic peak $44.48{ }^{\circ} \mathrm{C}$ which was found to be similar to glass transition temperature of PLGA polymer. The absence of endothermic transition of $\mathrm{VH}$ indicated the coating of drug due to formation of polymeric nanoparticles. 


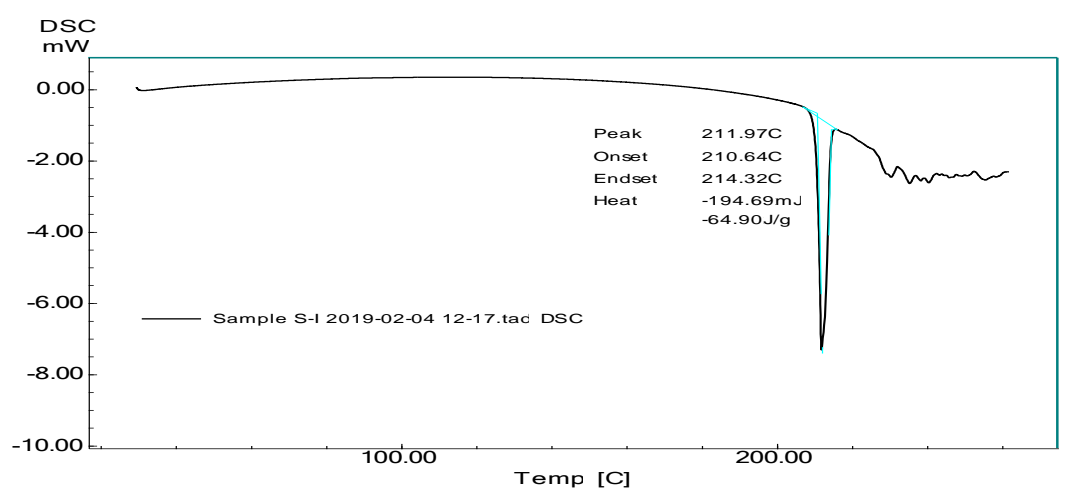

A

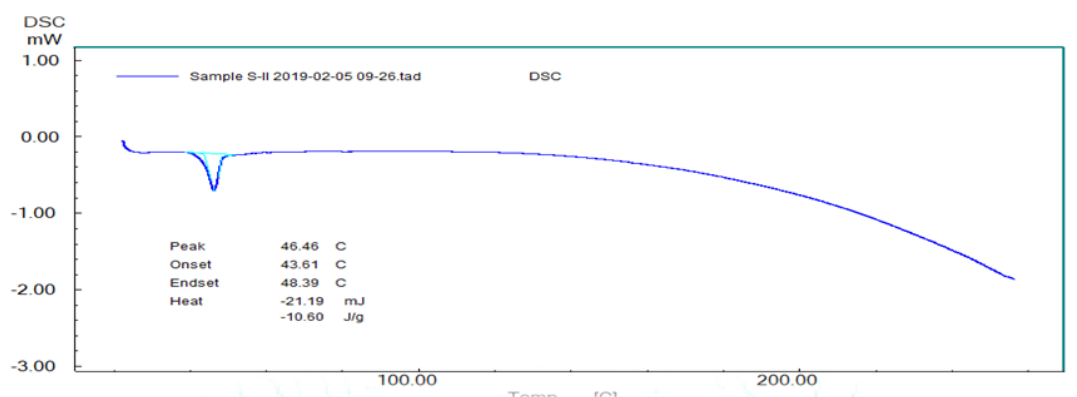

B

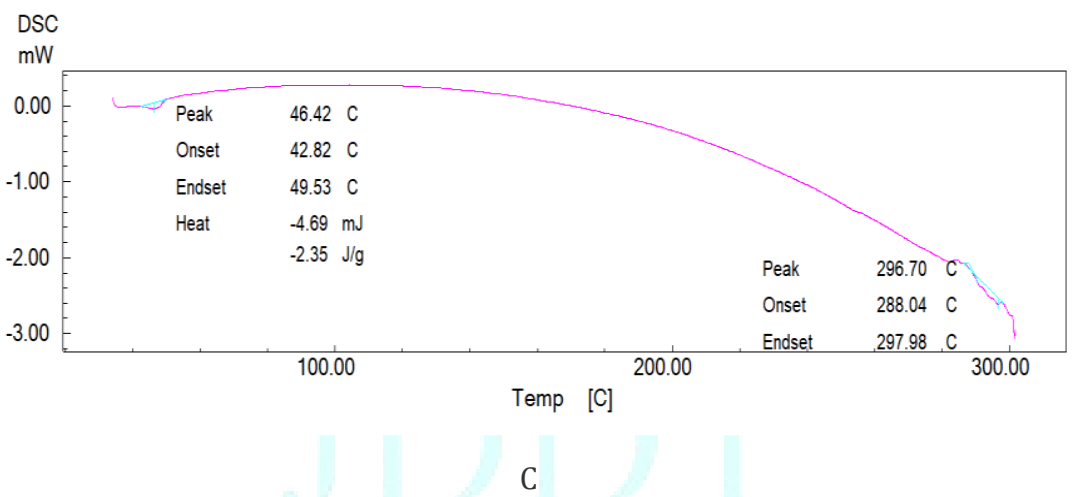

Fig. 5 DSC thermogram of VH, PLGA and VH loaded PNPs(A) DSC thermogram of VH (B) DSC thermogram of PLGA (C) DSC thermogram of VH loaded PNPs

\section{$X$ ray diffraction spectroscopy study}

The powder x-ray diffraction spectrum of VH, PLGA polymer and VH loaded PLGA nanoparticles were reported at an angle $2 \theta$ (Fig. 6). The following sharp peaks with intensities were observed at an angle $2 \theta$ at $6.82,8.15,10.34,12.83$, $13.62,15.13,17.44,18.35,19.88,21.32,21.85,22.61,22.89$, $25.19,26.43,27.33,28.68,31.22,33.35,34.14,35.20,37.77$ The sharp crystalline peaks at an angle $2 \theta$ confirmed the crystalline characteristics of VH. In case PLGA polymer the diffused pattern was observed and no sharp crystalline peak was present in the x-ray diffraction spectra. It indicating amorphous characteristics of the PLGA polymer. VH loaded polymeric PLGA nanoparticles has shown a diffused pattern in the X-RD spectra. It indicating the formation of nanoparticles. The PLGA polymer coat being present on drug molecule, hence the crystalline characteristics of VH was not observed in X-ray diffraction spectrum of polymeric NPs as shown in fig. 6 (A), (B), (C) respectively. 


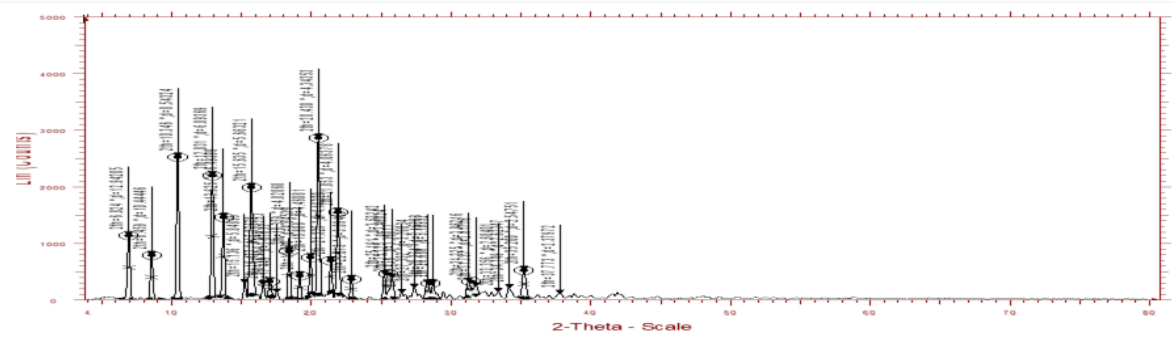

A

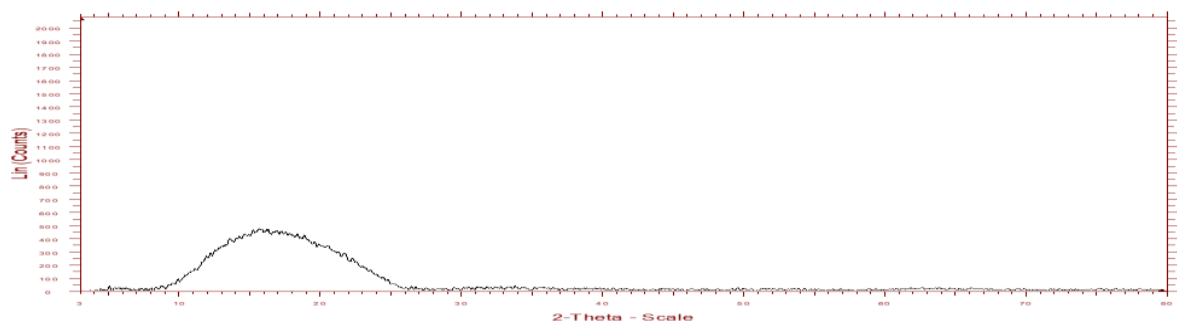

B

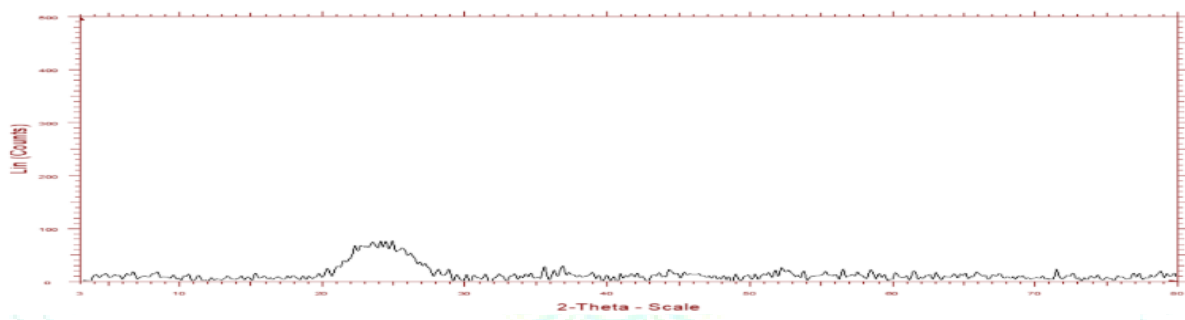

C

Fig. 6 X-RD spectrum of VH, PLGA and VH loaded PNPs (A) X-RD spectrum of VH (B) X-RD spectrum of PLGA (C) X-RD spectrum of VH loaded PNPs

\section{Surface morphology study}

Scanning electron microscopy of lyophilized VH loaded polymeric PLGA nanoparticles is shown in fig 7. A wellformed spherical polymeric nanoparticles containing $\mathrm{VH}$ were observed.

\section{Ex-vivo permeation study}

The ex-vivo permeation study $\mathrm{VH}$ was carried using ethanol, propylene glycol and their binary combinations with distilled water in various proportions and penetration enhancers were studied for their effect on skin permeation (Table 7).

Table 7 Ex-vivo effect of the solvent systems, permeation enhancers and nanoparticles on lag time, flux, and permeation parameters of $\mathrm{VH}$

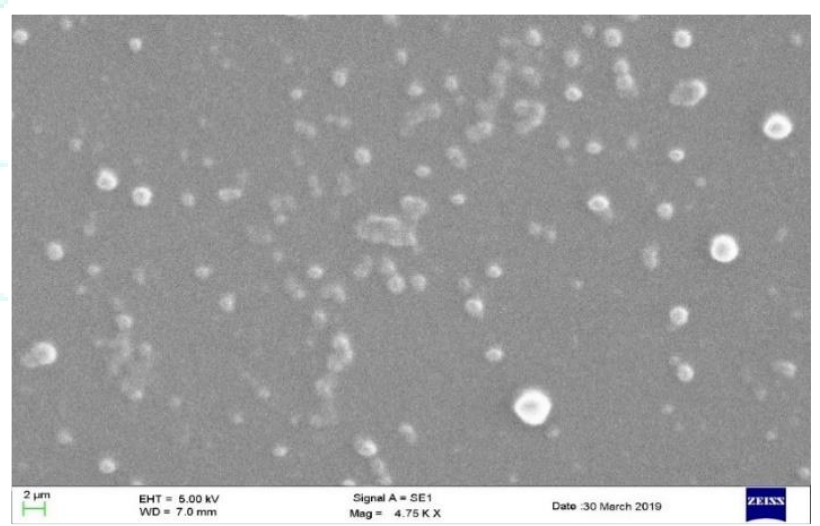

Fig. 7 Scanning electron microscopy study of VH loaded polymeric PLGA nanoparticles 
Table 7 Ex-vivo effect of the solvent systems, permeation enhancers and nanoparticles on lag time, flux, and permeation parameters of $\mathrm{VH}$

\begin{tabular}{|c|c|c|c|c|c|c|}
\hline Sr. No. & $\mathrm{FC}$ & $\begin{array}{c}\text { SS } \\
\text { PE } \\
\text { PNPS }\end{array}$ & $\begin{array}{l}\text { Lag time } \\
\text { (h.) }\end{array}$ & $\begin{array}{c}\text { Flux } \\
(\mu \mathrm{g} / \mathrm{cm} 2 / \mathrm{h})\end{array}$ & $\begin{array}{c}\text { Steady state } \\
\text { permeability } \\
\text { coefficient } \\
\left(\mathrm{K}_{\mathrm{p}}\right)(\mathrm{cm} / \mathrm{h})\end{array}$ & $\begin{array}{c}\text { Enhancement } \\
\text { ratio } \\
\text { (ER) }\end{array}$ \\
\hline 1 & W & DW (Control) & $6.22 \pm 0.26$ & $79.65 \pm 1.2$ & 2.12 & 1.0 \\
\hline 2 & NPs & Nanoparticles & $4.22 \pm 0.14$ & $192.24 \pm 3.6$ & 5.12 & 2.41 \\
\hline 3 & V1 & $33 \%$ EtoH in DW & $5.80 \pm 0.19$ & $114.75 \pm 1.9$ & 3.06 & 1.44 \\
\hline 4 & V2 & $50 \%$ EtoH in DW & $5.58 \pm 0.15$ & $137.08 \pm 2.7$ & 3.65 & 1.72 \\
\hline 5 & V3 & $66 \%$ EtoH in DW & $5.49 \pm 0.20$ & $142.30 \pm 2.9$ & 3.79 & 1.78 \\
\hline 6 & V4 & $100 \%$ EtoH & $6.00 \pm 0.28$ & $118.29 \pm 2.6$ & 3.15 & 1.48 \\
\hline 7 & V5 & $33 \% \mathrm{PG}$ in DW & $5.86 \pm 0.21$ & $106.41 \pm 2.1$ & 2.83 & 1.33 \\
\hline 8 & V6 & $50 \%$ PG in DW & $5.73 \pm 0.13$ & $111.69 \pm 2.5$ & 2.97 & 1.40 \\
\hline 9 & V7 & $66 \%$ PG in DW & $5.62 \pm 0.26$ & $122.78 \pm 2.8$ & 3.27 & 1.54 \\
\hline 10 & V8 & $100 \%$ PG & $6.12 \pm 0.34$ & $85.82 \pm 1.0$ & 2.28 & 1.07 \\
\hline 11 & V9 & 33\% PG in EtoH & $5.52 \pm 0.23$ & $150.22 \pm 1.9$ & 4.00 & 1.88 \\
\hline 12 & V10 & $50 \%$ PG in EtoH & $5.60 \pm 0.16$ & $158.67 \pm 2.9$ & 4.23 & 1.99 \\
\hline 13 & V11 & $66 \%$ PG in EtoH & $6.00 \pm 0.28$ & $147.05 \pm 2.7$ & 3.92 & 1.84 \\
\hline 14 & V12 & $\begin{array}{l}\text { 5\% Cineole (50\% PG } \\
\text { in EtoH) }\end{array}$ & $5.77 \pm 0.17$ & $177.20 \pm 3.4$ & 4.72 & 2.22 \\
\hline 15 & V13 & $\begin{array}{l}\text { 5\% Limonene }(50 \% \\
\text { PG in EtoH) }\end{array}$ & $3.17 \pm 0.11$ & $200.47 \pm 3.6$ & 5.34 & 2.51 \\
\hline 16 & V14 & $\begin{array}{l}5 \% \text { Menthol }(50 \% \\
\text { PG in EtoH) }\end{array}$ & $5.90 \pm 0.19$ & $163.52 \pm 2.9$ & 4.36 & 2.05 \\
\hline
\end{tabular}

Data were expressed as Mean \pm SD $(n=3)$

FC- Formulation code, SS-solvent system, PE-permeation enhancers, PNPs- polymeric poly (lactic co-glycolic acid), DW- distilled water, PG- propylene glycol, EtOH- Ethanol, Kp- Permeability coefficient, ER-Enhancement ratio

In the ex-vivo skin permeation studies of $\mathrm{VH}$ using distilled water as solvent system shown the lag time $6.22 \mathrm{~h}$ and flux value $79.65 \mu \mathrm{g} / \mathrm{cm}^{2} / \mathrm{h}$ was observed and was treated as control. The binary combinations of ethanol $33 \%$ to $66 \%$ in distilled water has shown decreased lag times $(5.80 \pm 0.19$, $5.58 \pm 0.155 .49 \pm 0.20$ ) and the flux values were found to be increased $(114.75 \pm 1.9,137.08 \pm 2.7,142.30 \pm 2.9)$. At $100 \%$ ethanol, lag time was found to be further enhanced $(6.00 \pm$ $0.28 \mathrm{~h}$ ) and the flux value was also reduced $(118.29 \pm 2.6)$ as compared to $66 \%$ ethanol in distilled water and control. Since VH is water soluble drug, the increasing concentration of ethanol may have increased the bilayer fluidity which can be explained by the increased in rate and amplitude of translational and rotational motion of individual of $-\mathrm{CH}$ group of acyl chain of lipids of stratum corneum. The increased lag time at $100 \%$ ethanol concentration may be due to dehydration of skin which results in increased tortuosity of diffusion pathway (Bommanan et al.1991). As compared to control, in case of ethanol lag time was found to be higher but was decreased with increasing ethanol concentration up to $66 \%$ as shown in fig.8 (A), (B), (C) respectively.

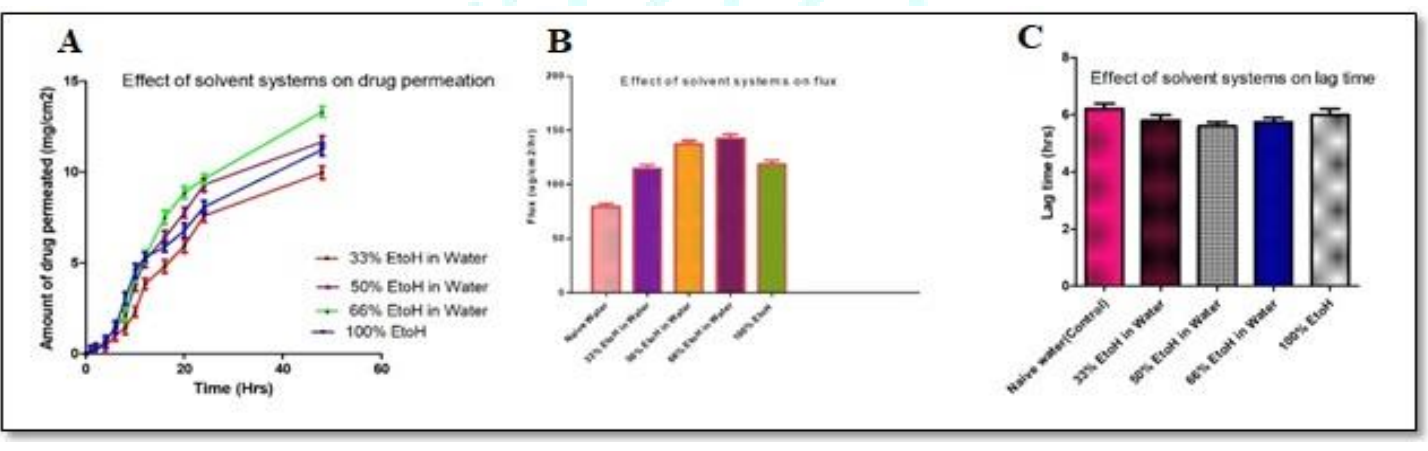

Fig. 8 Effect of solvent system on (A) amount of drug permeation (B) flux (C) lag time (33\% - 100\% EtOH in DW)

Propylene glycol in distilled water in concentration 33 to $66 \%$ shown decreased lag time values (5.86 $\pm 0.21,5.73 \pm$ $0.13,5.62 \pm 0.26$ ) and the lag time value was found to be lower than control $(6.22 \pm 026)$ and at $100 \%$ PG the maximum lag time was observed (6.12 \pm 0.34$)$ (Table 7). Similarly, the flux value was found to increase (106.41 \pm 2.1 , $111.69 \pm 2.5,122.78 .28 \pm 2.8$ ) from $33 \%$ to $66 \%$ PG in distilled water but the flux was decreased $(85.82 \pm 1.0)$ at $100 \% \mathrm{PG}$ as shown in Fig.9 (A), (B), (C) respectively. It is due to hygroscopic nature of PG, since PG forms pools inside skin, thereby leading to dehydration of skin (Ostrenga et al. 1971). The pool formation in skin is expected at all concentrations of PG but at 100\% PG free water present was negligible to satisfy the hydration requirement of $P G$. Thus at $100 \%$ PG extracts water from skin bilayers and corneocytes pockets and leading to increasing in barrier property of stratum corneum. 


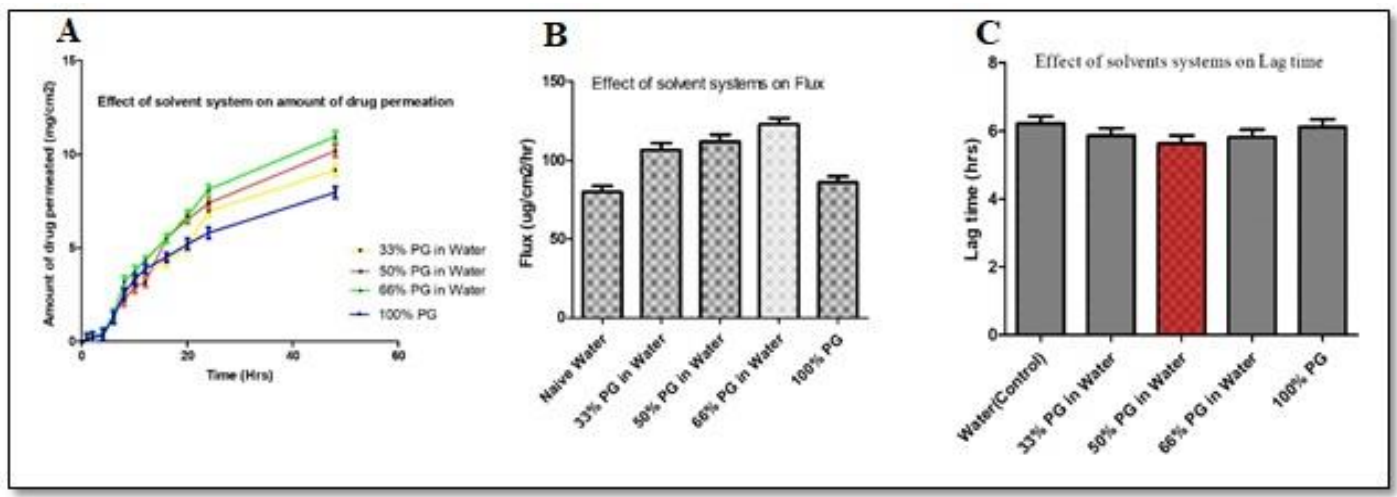

Fig. 9 Effect of solvent system on (A) amount of drug permeation (B) flux (C) lag time (33\% to 100\% PG in DW)

The lag time in binary combinations of propylene glycol in ethanol in 33,50 , and to $66 \%$ were found $5.52 \pm 0.23$, $5.60 \pm 0.16,6.00 \pm 028$ respectively. The lag time was found to increase with increasing concentration of $\mathrm{PG}$ in ethanol. The flux value in 33,50 , and to $66 \%$ PG in ethanol were found to be $150.22 \pm 1.9,158.67 \pm 2.9,147.05 \pm 2.7 \mu \mathrm{g} / \mathrm{cm} 2 / \mathrm{h}$. With the binary combination $33 \%$ and $50 \%$ PG in ethanol, flux were found to be enhanced but at $66 \%$ PG in ethanol the flux was further decreased as shown in fig. 10 (A), (B), (C) respectively.

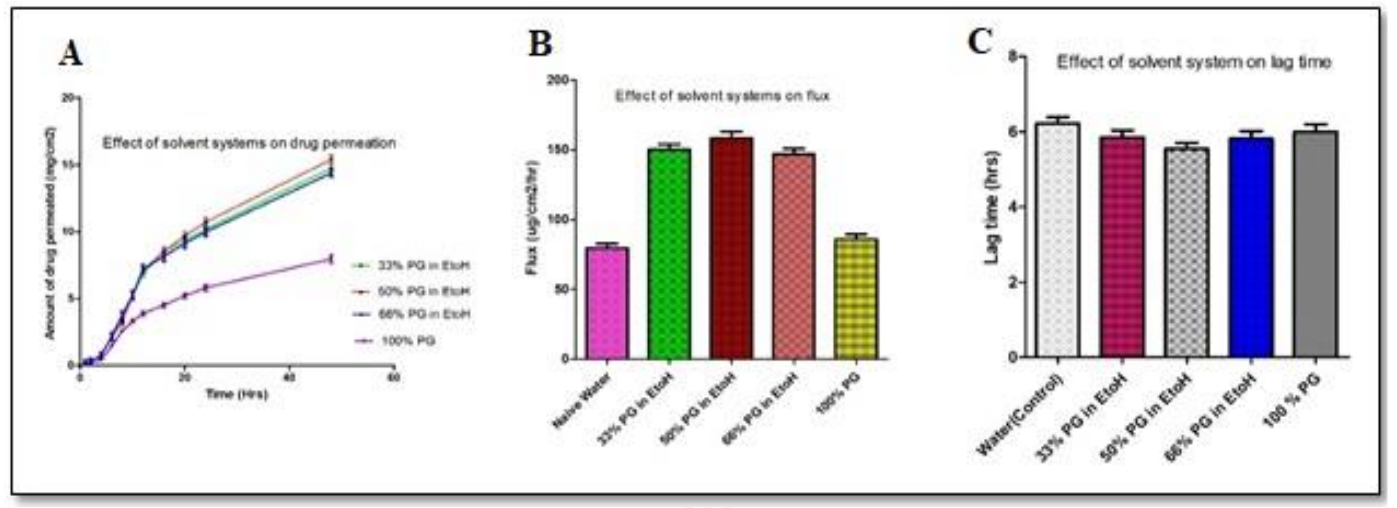

Fig. 10 Effect of solvent system on (A) amount of drug permeation (B) flux (C) lag time (33 -66\% PG in EtOH)

d) From above solvent systems, the solvent systems comprising $50 \%$ propylene glycol in ethanol shown maximum flux value and minimum lag time as compared to control. Hence the effect of penetration enhancers cineole, limonene, and menthol in $5 \%$ concentrations were studied in the above solvent system. The minimum lag time value was observed with 5\% limonene in 50\% PG in ethanol and shown the highest flux (200.47 \pm 3.6) than control $(79.65 \pm 1.2)$ as shown in Table 7 and fig. 11(A), (B), (C) respectively. Hence, we can conclude that the above solvent system can be used for the transdermal drug delivery of $\mathrm{VH}$.

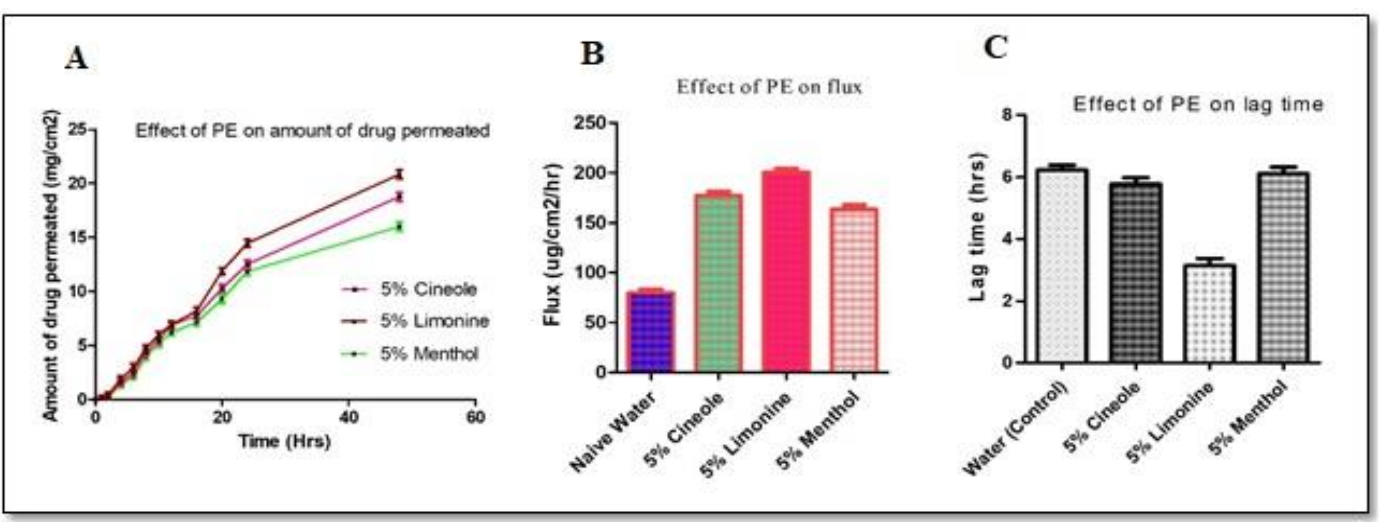

Fig. 11 Effect of permeation enhancers on (A) amount of drug permeation (B) flux (C) lag time (5\% PE) 
The meaningful plasma level concentrations can be achieved by taking considerations by flux value, clearance value of drug and surface area of transdermal patch.

\section{Pharmacokinetic parameters of VH}

$\mathrm{CL}=1.3 \pm 0.6$ liter $/$ hour $/ \mathrm{kg}$

$\mathrm{V}_{\mathrm{d}}=7.5 \pm 3.7$ liter $/ \mathrm{kg}$

$\mathrm{T}_{1 / 2}=5 \pm 2$ hours

$\mathrm{BA}=42 \pm 15 \%$

\section{$\mathrm{C}=(\mathrm{Ja} \times \mathrm{Sa}) / \mathrm{CL}$}

Where, $\mathrm{C}=$ Steady state plasma Concentration

$$
\begin{aligned}
\mathrm{Ja} & =\text { Flux } \\
\mathrm{Sa} & =\text { Surface area } \\
\mathrm{CL} & =\text { Clearance }
\end{aligned}
$$

The maximum flux achieved was $200.47\left[\mu \mathrm{g} / \mathrm{cm}^{2} / \mathrm{hr}\right]$

$$
\mathrm{C}=(\mathrm{Ja} \times \mathrm{Sa}) / \mathrm{CL}
$$

$200.47\left[\mu \mathrm{g} / \mathrm{cm}^{2} / \mathrm{h} \times \mathrm{Sa}\left[\mathrm{cm}^{2}\right]\right.$

C $=0,000[\mathrm{~mL} / \mathrm{h}]$

Steady state concentrations of $\mathrm{VH}$ from $12.85 \mathrm{ng} / \mathrm{mL}$ to $128.5 \mathrm{ng} / \mathrm{mL}$ can be obtained with patch size of $5 \mathrm{~cm}^{2}$ to 50 $\mathrm{cm}^{2}$ respectively shown in table 8.

Table 8 Steady state concentration of $\mathrm{VH}$

\begin{tabular}{lll}
\hline Sr. No. & $\begin{array}{l}\text { Surface area of } \\
\text { patch }\left(\mathrm{cm}^{2}\right)\end{array}$ & $\begin{array}{l}\text { Steady state plasma } \\
\text { level of } \mathrm{VH}(\mathrm{ng} / \mathrm{mL})\end{array}$ \\
\hline 1 & 5 & 12.85 \\
\hline 2 & 10 & 25.70 \\
\hline 3 & 20 & 51.40 \\
\hline 4 & 30 & 77.10 \\
\hline 5 & 40 & 102.8 \\
\hline 6 & 50 & 128.5 \\
\hline
\end{tabular}

\section{CONCLUSION}

Nanoparticles represent a tool to transport the necessarily drugs across the BBB that normally are unable to cross this barrier. Drug that have successfully have been transported into the brain using this carrier include polymeric poly (lactic co-glycolic acid). Tween-80 was used as surfactant in nanoparticle formulation.

Ex-vivo skin permeation study of $\mathrm{VH}$ was carried out in different solvent systems and results indicated that solvent system comprising $50 \% \mathrm{PG}$ in ethanol shown maximum flux of $158.67 \pm 2.9 \mu \mathrm{g} / \mathrm{cm}^{2} / \mathrm{h}$ and lag time $5.60 \pm 0.16 \mathrm{~h}$, maximum permeability coefficient $4.23 \mathrm{~cm} / \mathrm{h}$ and maximum enhancement ratio 1.99 was observed as compared to other solvent systems studied.

Ex-vivo skin permeation study of $\mathrm{VH}$ was carried out in different PEs and results indicated that $5 \% \mathrm{v} / \mathrm{v}$ limonene shown maximum flux $200.47 \pm 3.6 \mu \mathrm{g} / \mathrm{cm}^{2} / \mathrm{h}$ and least lag time of $3.17 \pm 0.11 \mathrm{~h}$, maximum permeability coefficient 5.34 $\mathrm{cm} / \mathrm{h}$ and maximum enhancement ratio 2.51 was observed as compared to other PEs. The rank order was observed for skin permeation of VH in different PEs: limonene > cineole > menthol. Limonene was increasing partitioning of a drug into stratum corneum which leads to increased permeation rate of drug.

Ex-vivo skin permeation study of VH -PPNPs was carried out and compared with control group (distilled water) and results indicated that VH -PPNPs shown maximum flux of $192.24 \pm 3.6 \mu \mathrm{g} / \mathrm{cm}^{2} / \mathrm{h}$ and least lag time $4.22 \pm 0.14 \mathrm{~h}$, maximum permeability coefficient $5.12 \mathrm{~cm} / \mathrm{h}$ and maximum enhancement ratio 2.41 was observed as compared to control group (distilled water).

From the above observation, it was concluded that combination of optimized solvent system $(50 \%$ PG in ethanol), optimized PE (5 \%v/v limonene) and VH-PPNPs may be choice for use in a novel transdermal formulation of $\mathrm{VH}$.

Based on the clearance value of $\mathrm{VH}(78000 \mathrm{~mL} / \mathrm{h})$, maximum flux value obtained $200.47 \pm 2.54(\mu \mathrm{g} / \mathrm{cm} 2 / \mathrm{h})$ and by varying the surface area of the transdermal patch from $5 \mathrm{~cm}^{2}$ to 50 $\mathrm{cm}^{2}$, a meaningful plasma level concentration of $\mathrm{VH}$ ranging from 12.85 to $128.5 \mathrm{ng} / \mathrm{mL}$ can be achieved.

\section{REFERENCES}

1. Abbott N., Patabendige A., Dolman D., Yusof S., Begley D. (2010) Structure and function of the blood-brain barrier, Neurobiology of Disease 37, 13-25, DOI: 10.1016/j.nbd.2009.07.030

2. Acharya S. and Sahoo S., (2011) PLGA nanoparticles containing various anticancer agents and tumour delivery by EPR effect, Advanced Drug Delivery Reviews 63, 170-183, DOI: $10.1016 /$ j.addr.2010.10.008

3. Alexis F, Pridgen E, Molnar LK, Farokhzad OC (2008) Factors affecting the clearance and biodistribution of polymeric nanoparticles. Mol Pharm 5(4):505-515. DOI:10.1021/ mp800051m

4. Anderson J. and Shive M. (1977) Biodegradation and biocompatibility of PLA and PLGA microspheres. Advanced Drug Delivery Reviews, 28(1):5-24. PMID:10837562

5. Barch D., (2013) Introduction to Special Issue on the Neurobiology of Depression, Neurobiology of Disease 52, 1-3 DOI.org/10.1016/j.nbd.2012.10.026

6. Bellavance M., Blanchette $M$ and Fortin D., (2008) Recent Advances in Blood-Brain Barrier Disruption as a CNS Delivery Strategy, The AAPS Journal, 10(1):166-177, DOI: 10.1208/s12248-008-9018-7

7. Bilati U., Alle E. and Doelker E. (2005) Poly (D,L-lactide-coglycolide) protein-loaded nanoparticles prepared by the double emulsion method-processing and formulation issues for enhanced entrapment efficiency, Journal of

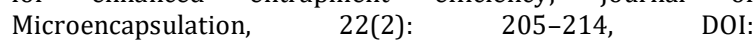
$10.1080 / 02652040400026442$

8. Bommannan. D., Russell P., and Guy R. (1991) Examination of the effect of ethanol on human stratum corneum in-vivo using infrared spectroscopy, Journal of Controlled Release, 16 299304, PMID:5127090

9. Danhier F., Ansorena E., Silva J., Coco R., Breton A., Preat V., (2012) PLGA-based nanoparticles: An overview of biomedical applications, Journal of Controlled Release 161;505-522, DOI:10.1016/j.jconrel.2012.01.043

10. Dinas P., Koutedakis Y., Flouris Y., (2011) Effects of exercise and physical activity on depression, Ir J Med Sci 180:319-325, DOI 10.1007/s11845-010-0633-9

11. Gohel M., and Bariya S., (2009) Advanced formulation design of $\mathrm{VH}$ coated and triple-layer tablets containing Hypromellose, Pharmaceutical Development and Technology, 14(6): 650658, DOI: $10.3109 / 10837450902911911$

12. Gulati N, Nagaich U, Saraf S,(2014) Fabrication and in-vitro characterization of polymeric nanoparticles for Parkinson's therapy: a novel approach, Brazilian Journal of Pharmaceutical 
Sciences, vol. 50(4) DOI.org/10.1590/S198482502014000400022

13. Katara R., Sachdeva S., and Majumdar D., (2017) Enhancement of ocular efficacy of aceclofenac using biodegradable PLGA nanoparticles: formulation and characterization, Drug Deliv. and Transl. Res. DOI:10.1007/s13346-017-04161

14. Krishnaiah Y., and Al-Saidan S., (2008) Limonene Enhances the In-Vitro and In-Vivo Permeation of Trimetazidine Across a Membrane-Controlled Transdermal Therapeutic System, Current Drug Delivery, 5, 70-76, PMID:18220554

15. Lopez E., Ettcheto M., Egea1 M., Espina M., Cano A., Calpena A., Camins A., Carmona N, Silva A., Souto E.

16. and García M., (2018) Memantine loaded PLGA PEGylated nanoparticles for Alzheimer's disease: in-vitro and in-vivo characterization, J Nanobiotechnology, 16:32 https://doi.org/10.1186/s12951-018-0356-z

17. Narishetty R., Sunil T., (2005) Effect of l-menthol and 1,8cineole on phase behavior and molecular organization of SC lipids and skin permeation of zidovudine. J. Control. Release 102, 59-70 DOI:10.1016/j.jconrel.2004.09.016

18. Ng K, Xiong S, Zhao X, Heng B, Loo J, (2011) Cellular uptake of poly-(D,L-lactide-co-glycolide) (PLGA) nanoparticles synthesized through solvent emulsion evaporation and nanoprecipitation method, Biotechnol. J. 6, 501-508 DOI 10.1002/biot.201000351

19. Ostrenga J., Steinmetz C., Poulsen B., (1971) Significance of Vehicle Composition I: Relationship between Topical Vehicle Composition, Skin Penetrability, and Clinical Efficacy, Journal of Pharmaceutical sciences, 60(8);1175-1179. DOI :https://doi.org/10.1002/jps.2600600812

20. Panchagnula R., Salve P., Thomas N., Jain A., Poduri R., (2001) Transdermal delivery of naloxone: effect of water, propylene glycol, ethanol and their binary combinations on permeation through rat skin, International Journal of Pharmaceutics 219, 95-105 PMID:11337170

21. Panchagnula R., Bokalial R., Sharma P., Khandavilli S., (2005) Transdermal delivery of naloxone: skin permeation, pharmacokinetic, irritancy and stability studies, International Journal of Pharmaceutics 293, 213-223, DOI:10.1016/j.ijpharm.2005.01.004
22. Patel H., Shah S., Shah D., Joshi P., (2011) Sustained release of venlafaxine from venlafaxine-montmorillonitepolyvinylpyrrolidone composites. Appl. Clay Sci., 51, 126-130 DOI org/10.1016/j.clay.2010.11.013

23. Rao J., (2011) Geckeler K., Polymer nanoparticles: Preparation techniques and size-control

24. Parameters, Progress in Polymer Science 36 (2011) 887-913, DOI 10.1016/j.progpolymsci.2011.01.001

25. Sawant K., Seju U., Kumar A., (2011) Development and evaluation of olanzapine-loaded PLGA nanoparticles for noseto-brain delivery: In-vitro and in-vivo studies, Acta $\begin{array}{llll}\text { Biomaterialia } & 7 & \text { (2011) }\end{array}$ DOI:10.1016/j.actbio.2011.07.025

26. Shah D., Khandavilli S. and Panchagnula R., (2008) Alteration of Skin Hydration and its Barrier Function by Vehicle and Permeation Enhancers: A Study using TGA, FTIR, TEWL and Drug Permeation as Markers, Methods Find Exp Clin Pharmacol, $\quad 30(7): \quad 499-512$ DOI: 10.1358/mf.2008.30.7.1159653

27. Tosi G, Costantino L, Ruozi B, Forni F, Vandelli A., (2008) Polymeric nanoparticles for the drug delivery to the central nervous system. Expert Opin. Drug Deliv. 5, 155-174 PMID:23458620

28. Tripathi K. D., (2009) Essentials of Medical Pharmacology, $6^{\text {th }}$ Edition, Jaypee Brothers Publishing House Pvt. Ltd. Reprint;476-556.

29. Vandervoort J, Ludwig A, (2002) Biocompatible stabilizers in the preparation of PLGA nanoparticles: a factorial design study, International Journal of Pharmaceutics 238,77-92 DOI org/10.1016/S0378-5173(02)00058-3

30. Yang Z., Teng, Y., Wang H., Hou H., (2013) Enhancement of skin permeation of bufalin by limonene via reservoir type transdermal patch: Formulation design and biopharmaceutical evaluation. Int. J. Pharm., 447, 231-240 DOI:10.1016/j.ijpharm.2013.02.048

31. Zhou Y, Zhang G, Rao Z, Yang Y, Zhou Q, Qin H, Wei Y, Wu X, (2015) Increased brain uptake of venlafaxine loaded solid lipid nanoparticles by overcoming the efflux function and expression of P-gp Arch. Pharm. Res. 38:1325-1335 DOI 10.1007/s12272-014-0539-6 